\title{
PEDAGOGICAL REFLECTION IN THE MODELING OF THE PURPOSES OF THE PROFESSIONAL PREPARATION OF THE FUTURE SPECIALISTS
}

\author{
Oksana Kulida \\ Postgraduate Student, Bogdan Khmelnitsky Melitopol State Pedagogical University, Ukraine \\ e-mail: oksana.kulida20@ukr.net, orcid.org/0000-0003-1278-7253
}

\section{Summary}

The problem of the use of the pedagogical reflection in the process of the professional preparation of the future specialists has been actualized in the article, in particular based on the analysis of the experience of its use in the realization of the educational-professional program of the future bachelors of the law. The new knowledge has been represented with the complementarity of the known methodological approaches to the use of the pedagogical reflection in the modeling of the purposes of the educational-professional program, the new interpretation of the pedagogical reflection and the generalization of the experience of the use and the approbation of the reflexive procedures of the value-semantic direction.

In the research of the question from the point of view, the contradictions of the realization of the pedagogical reflection have been determined; the factors of the influence on the modern process of the building of the educational-professional models have been installed; at the level of the philosophical methodology, the new worldview positions of Homo educandus have been explained, which influence significantly on its value-motivational choice of the personal-educational trajectory. The role of the pedagogical reflection in the process of the general cultural and the professional development of the future bachelor of the law has been installed. The possibilities of the pedagogical reflection in the procedure of the formation of the purposes of the professional preparation, in particular the modeling of the process of the teaching have been characterized. The methodological references-points have been presented with the need of the consideration in the educational programs' changes that have been occurred in the public consciousness and the worldview of the human at the present stage of the development of the community (the post-metaphysical thinking, the linguistic turn, the refusal of the recognition of the advantage of the theory over the practice, the concretization of the mind); the methodology of the value-semantic sending of the pedagogical reflection, the conceptualization of the pedagogical reflection as the special philosophical-educational procedure of the "embedding" of the student in the general cultural meanings of the past, of the present and of the future of the common vital activity of the subjects of the single cultural-educational space.

Keywords: axiological approach, complementarity, communicative-dialogical competence, meta-activity, methodology, thinking, educational-professional program, worldview changes, philosophical-educational reflection.

\section{DOI: https://doi.org/10.23856/3821}

\section{Introduction}

Today the advancement of the society in the measurement of its iconic of the educational-cultural markers has appeared in the most researched sources as the "information society". But, we think, that more correct name of this historical form of the existence of the human and the society on the global scope should be the name of the "information society", which has come to replace the "society of the knowledge" and it has affected significantly all spheres of the vital 
activity of the human. The spread of the informative factors in the culture of the individual has changed significantly his worldview position, which can be defined as the new worldview movement (J. Habermas), which, first of all, has been touched the young people, who study and who are disposed to the perception of the new knowledge, the new technologies, the new forms of the educational and the professional activities. The "the society of the knowledge", which has failed to harmonize the dynamics and the dialectics of the objective and the subjective factors of the development of Homo educandus in the purposes and the contents of the education, in particular in the professional preparation of the applicants of the higher education, it has given way to the informative way of the teaching and the vital activity. The large number of the researches show that the presence of the certain achievements in the democratization and the modernization of the higher education in the process of its informatization, and the significant problems that need immediate comprehension (Aron, 2012; Bauman, 2004; Habermas, 1988; Lonergan, 2010; Troitska, Osadchyi, 2019 and other researchers).

The significant part of these problems is associated with the presence of the huge number of the informative, the digital technologies, the programs of the teaching and the insufficient analytics and the value-semantic reflection of the educational activities, which should be added to the modeling of the informatization and the educational processes of the communicative-dialogical direction, and also as in the conceptual and in the contextual measurement to strengthen the personal (in the form) and the axiological and the praxeological (in the essence) nature of the extraction of the qualification in the higher education.

At the same time, based on the analysis of the research literature in the subjectivity of the pedagogical modeling, in particular the process of the formation of the purposes and the contents of the professional preparation of the bachelors of the law, we have been noted several contradictions:

- in the innovative move of the pedagogy, that uses in the modeling of the processes and the actions of the normative documents, the expert assessments, the empirical material, first of all, the new worldview changes in the modern education are not always taken into account;

- the modeling takes place mostly within the technocratic paradigm of the preparation of the future specialist, in which the model of the professional personality is strictly regulated, which is not always based on the pedagogical technologies with the creative, with the personal orientations and the reflective procedures;

- the pedagogical reflection and the reflection of all subjects of the pedagogical process are insufficiently involved in the construction of the educational trajectories of the personality, and also there is a lack of the awareness of the complexity of the phenomenon of the reflection and its methodological potential.

That is why the scientific novelty will be represented with the complementarity of the known methodological approaches to the use of the pedagogical reflection in the modeling of the educational purposes and the professional self-determination, the new interpretation of the pedagogical reflection and the generalization of the experience of the use and the approbation of the reflexive procedures of the value-semantic direction.

The research of the question enables, from the new point of view, the solution of the contradictions that has led to the purpose of our research such as to determine the methodological references-points of the pedagogical reflection in the modeling of the purposes of the professional preparation of the bachelor of the law and to install the factors of the influence on the modern process of the building of the educational-professional model, which, in our opinion, cannot be the educational-professional program.

This new aspect of the research is realized in the process of the implementation of the following tasks: 
- at the level of the philosophical methodology to explain the new worldview of the positions of Homo educandus, which affect significantly its value-motivational choice of the personal-educational trajectory;

- to determine the role of the reflection in the process of the general cultural and the professional self-determination of the future bachelor of the law;

- to install the possibilities of the pedagogical reflection in the procedure of the formation of the purposes of the professional preparation, in particular the modeling of the process of the teaching.

\section{The worldview factors of the modern higher education}

If the changes will be crystallized, which have been occurred in the social consciousness and the worldview of the human, it should be talked about four methodological moves: the post-metaphysical thinking, the linguistic turn, the refusal of the recognition of the advantage of the theory over the practice, the concretization of the mind (Habermas, 1988). It should be recognized that these changes in the human consciousness are associated with the "postmodern" culture, which is characterized with the overstatement of the novelty of own vital activity of the human, too "critical" attitude to the experience of the previous generations, the overstatement of the importance of their "truth", their microcosm, the lack of the level of the conversance, the will, etc. In such conditions, the methodology of the building of the personal trajectories of the receiving of the higher education should be understood in terms of not only as the organizational-practical, but it is also the worldview-semantic (Troitska, 2019).

That is why in the actualization of the mentioned problem we give the prominent place to the modeling of the pedagogical activity as the reproduction of the reality, as the visual representation of the properties of the researched object, which is "formalized, simplified" in the model, but this procedure facilitates the reproduction of the properties, the connections, the tendencies of the researched system and the processes and it allows summing up their condition, making the forecast, making the well-grounded decision.

In the diversity of the forms of the modeling, which depend on the structure of the model and the sphere of its application, many strategies, the technologies, the practices have been worked out, which are paid attention: the different approaches to the pedagogical modeling are in the works of A. Verbytskyi, P. Rastiannikov, O. Shavrina (Shavrina, 2000); the possibility of the modeling in the overcoming of the gap between the teaching and the education, between the procedural and the general cultural development of the personality of the future specialist, the principles of the model approach of the active socio-psychological teaching, the technology of the building of the models, the ways of the practical realization them in the group, the types of the didactic models and the role of the pedagogical reflection have been considered.

The target model is the subject of our interest, in which, according to O. Shavrina, "...the meaningful and the categorical purposes of the teaching are determined. The meaningful purposes are the specific knowledge, the skills and the abilities which subjects of the teaching must master. The categorical purposes are based on the working of so-called the taxonomies, that is the groups of the categories of the purposes, each of which express the certain totality and the sequence of the intellectual operations, such as the knowledge, the understanding, the use, the analysis, the synthesis, the mark. All conclusions which have been obtained on the correlation of the blocks of the material with the correlated meaningful purposes and also with the results of the teaching and, so, with the categorical purposes and they will be the target model of the process of the teaching" (Shavrina, 2000: 44). 


\section{The reflection in the pedagogical modeling}

The reflection as a product of the philosophizing in the understanding from the Renaissance has been taken the worthy place in the culture of the thinking as the source of the cognition (J. Locke), as the transcendental reflection, as the ability of the thinking (I. Kant), the absolute reflection as the dialectical methodology of the cognition (G. Hehel), as the phenomenon of the consciousness (E. Husserl), as the "producer" of the values of the true and the being, and others. The modern philosophy highlights the methodological functions of the reflection aimed at the reproduction by the thinking of the universal connections of the world, which it (thinking) has been considered in isolation (Bulatov, 2009: 425), which is characterized the reflection as the self-consciousness and the self-knowledge, the correlation of the elements of the thinking and the reality. It is no coincidence that $\mathrm{D}$. Borkhers defines the reflection as the standard of the scientific methodology and the moderator of the interdisciplinary dialogue.

In this sense, the understanding of the the reflection as "the process of the comprehension of something with the help of the study and the comparison... and the "new turn" of the spirit after the implementation of the cognitive act to the I (as the center of the act and its microcosm) is deserved to the attention, thanks to it becomes possible to appropriate what has been known" (Philosophical Encyclopedic Dictionary, 2002: 394). Actually, it should be returned to the opinion of B. Lonergan, who, in our opinion, has deployed the essence of the reflection in its pedagogical form, developing the doctrine of the functional specialization of the theology and the criterion-defining value as the transcendental idea, he wrote: "The value is intensified in the questions, which require the thinking just as intelligible is intensified in the questions that require the intellect, and the true and the being is intensified in the questions that require reflection" (Lonergan, 2010).

As in the process of the modeling of the purposes and the contents of the education there is both the methodology of the new construction and some awareness of this methodology by the participants of the modeling, so the pedagogical reflection, in our opinion, should have double character: on the one hand, the methodology of the search and the creation of the new requires clear criteria of its creation on the principle of the efficiency, the intellectuality and the ethics, on the other hand, it is the a reflection of the values-worldviews position of the applicants of the professional education, who do not present the rigid professional model of the future specialist and his image.

\section{The pedagogical reflection in the modeling of the purposes of EPP from the practical experience}

As it has been mentioned above, today the positions of the subjects of the higher education should take into account in all components of the educational process, it is usually necessary to take into account the changes in the worldview of the young people. As, if we interpret the post-metaphysical thinking as one that reflects the paradigmatic orientation to waive the presumption of the possibility of the building of the single conceptual model of the world, or the process or the event, and also to understand that it differs from the desire of the appropriateness, the conformity with the maxims, the norms, the sustainable principles, so, it is necessary to use the information discursive variants of the decision of the problem only in the dialogical way (Troitska, 2016).

It means for us that the motivational and the cognitive component of the teaching and the choice of the personal educational trajectory, in particular the purpose of the education, it 
should be on the principle of the complementarity which is added with the communicative-dialogical. It, involving the reflection, fills the choice of the purposes with the meanings and the values of all participants of the process. In this way, a person has the wide opportunities of the building their own trajectories in the informative space and the integrity of the explicit and the implicit components of the reflection and the harmonization of the introverted and the extroverted features.

If in the purposes of the educational-professional program of the preparation of the bachelors of the law (hereinafter EPP) the formation of the ability to protect the rights and the freedom of the citizens guided by the principle of the rule of the law and followed the ethical standards of the legal branch, the providing of the appropriateness of the preparation of the Standards of the higher education in the specialty, the mission, the vision, the values of the university and the orientation on in-depth practical preparation of the qualified, the competitive, the competent graduates should be noted so, these references-points should be perceived by the subjects of the education not only as the appropriate, the normative, but also those that correspond their interests and the desire. That is why at the numerous meetings of the applicants of the higher education, of the lecturers and of the potential employers (stakeholders), the complex of the general and the special competencies has been processed reflexively, which has been supplemented with the formation of the values and the worldviews grounds of the future lawyers, their ability to realize the personal features, the worldview and the way of the thinking, and to develop as the creative person, the intellectual with the critical thinking and with the scientific worldview and as the educated conscious citizen [http://geo.mdpu.org.ua/prirodnicho-geografichnij-fakultet/kafedra-prava/osvitnij-protses-kafedri-prava/].

So, in this way the linguistic turn of the worldview "works", that provides the great opportunities of the "proclamation" of the informatization through the discursive practices as the "meetings" of the subjects of the different preferences, through the different linguistic constructions, the narratives, the dialogic interpretations, etc. The new knowledge, which has been enriched with the multicultural values and the meanings, it enables the way to common values and the meanings, to the adoption of the practical rules of the common mastering of the professional, the intellectual, the ethical and the spiritual norms of the common to all mankind life.

Moreover, in the communicative-dialogical activity there can be the constant increase of the level of the reflexive qualities of the personality of the future specialist, because in this activity both the external (the explicit) form of the reflection and the internal (the implicit) are interacted, the contradictions between the subject's expectations and the actual reaction of the object, etc. are interacted

For the understanding of the pedagogical reflection, it is also important comprehension of the reflexive-innovative process in the humanities, which are considered it in the different socio-cultural contexts (L. Vygotskyi, A. Leontiev, D. Elkonin, V. Slobodchikov, G. Shchedrovytskyi and others). The reflection in these contexts is understood not only as the process of the rethinking and the heuristic overcoming by the subject of the patterns of the thinking, but also as the new type of the thinking, the new way of the communication, including the different values- worldviews positions, the experience of the cultural-discursive practices and the individual-creative properties of the personality. Such model of the pedagogical reflection has the tendency, in our opinion, to become the certain methodological construct, in particular in the professional preparation of the future specialists at all levels of the methodology. This methodology orients the pedagogical reflection not on the comprehension of the technological processes of the teaching, but on the in-depth, thoughtful meta-activity as for the initial cause and the principles, which are the basis of thinking about the education, the culture, the personality, 
and so on, as the knowledge about the receiving of the new knowledge and the quintessence of the approaches, the principles and the methods of its growth, and as the requirement for the compliance in the researches and the activities of the cultural maxims.

We propose to consider the pedagogical reflection as the procedure of the philosophical activity, which is significantly different from many components of the philosophical fund (analysis, synthesis, homogenization, totalization, universalization, theorizing, generalization, etc.). Moreover, it is not the critical thinking, which is "promoted as a brand" today, but is formed, in our opinion, without the analytical techniques and the reduction of the creative thinking.

So, generalizing the experience of the reflective-pedagogical activities as for the modeling of the purposes of the educational-professional preparation of the future bachelors of the law, at the level of the specific (the philosophical-educational) methodology, we note:

- the pedagogical reflection should become thinking, which in form always returns to the subjectivity (in our case it is the purpose, the contents, the organizational-administrative conditions of the professional preparation of the future lawyers) conceptually to the ultimate, the marginal principles which are comprehended, the ways of its fixation, the different manifestations of the natural, the social, the cognitive, the anthropological factors;

- the reflection highlights the amplitudes (the originality of the subject, its spiritual formations, the beliefs and the ideals, the totality of the semantic, the value, the existential, the willed intentions and the determinations) of all subjects of the common activity;

- in such way, the reflection "builds" the modern students in the common to all mankind search, returning to the eternal sacramental questions (How? Why? What for?) to the past and the future (other contexts);

- perceiving unquestionably the position that the philosophical-pedagogical reflection, as the reflection of the second order (it theorizes not the subject of the reality, but the images, the notions and the categorical-logical forms of the reality), it deals with the ideas, the principles that stimulate spiritually the personality and it orients on the humanity of the purpose and the activities.

\section{Conclusions}

The research of the problem and its formulation in such aspect has been confirmed the actuality of the involvement in the innovative move of the pedagogy of the philosophical-educational reflection, which allows taking into account in the modeling educational processes and the actions of the worldviews of the attitude of the subjects of the education, the use of pedagogical technologies with creative, the personal orientations and the reflective methodological procedures of the axiological direction. The explication of the reflection, from the point of view of the modern philosophy, as the self-consciousness and the self-knowledge, as the correlation of the elements of the thinking and the reality, as a methodology which aimed at the reproduction in the process of the thinking of the universal connections of the world, as the standard of the scientific methodology and the moderator of the interdisciplinary dialogue, it gives the opportunity to prevent, on the one hand, the exaggerated reduction of the reflection to the partially-practical procedure and, on the other hand, it has generalized it to the thinking as such.

The functioning in the educational process and in the modeling it through EPP without the pedagogical reflection is not possible: neither motivational, nor cognitive, nor organizational-activity components of the teaching will become effective without students' choice of personal educational trajectory, in particular the purposes of the education, without the communicative-dialogic interaction and the consensus, without the common choice of the purpose 
based on the meanings and the values of all participants of the realization of the EPP process. In this way there are the wide opportunities of the building of the applicants of the higher education of their own trajectories of the move in the cultural-educational space and it provides (apodictically) the integrity of the explicit and the implicit components of the reflection and the harmonization of the introverted and the extroverted features of the subjects of the education.

The methodological receptions, namely: the approval in the consciousness of the human of the post-metaphysical thinking, the philosophical-linguistic comprehension of the reality, the concretization of the mind, the practice-oriented teaching and the education, the providing of the discursive communication, the communicative-dialogical interaction and the humanity (human dimension) of the subjects of the education should be the object of the deep pedagogical reflection of all components of the educational-professional process, and their research is the subject of our further scientific work.

\section{References}

Aaron R. (2012). Lektsii po filosofii istorii Lektsii po filosofii istorii [Lectures on the philosophy of history]. M.: Book House "LIBROCOM" [in Russian].

Bauman Z. (2004). Globalizatsiya. Posledstviya dlya cheloveka i obshchestva [Globalization. Consequences for man and society]. M.: Publishing House "Ves mir" [in Russian].

Bulatov M.O. (2009). Filosofs'kyy slovnyk [Philosophical dictionary]. K.: Stilos [in Ukrainian]. Philosophical encyclopedic dictionary (2002). Filosofskiy entsiklopedicheskiy slovar'. M.: INFRA-M [in Russian].

Habermas J. (1988). The unit of vanity in the multifaceted atmosphere. Nachmetaphysical thoughts. Frankfurt am Main: Suhrkamp.

Lonergan B. (2010). Metod v teologii [Method in theology]. M.: Institute of Philosophy, Theology and History of St. Thomas [in Russian].

Shavrina O.Yu. (2000) Pedagogicheskaya refleksiya uchitelya [Teacher's pedagogical reflection]. - Ufa: Institute of History, Language and Literature - UNS RAN; Sterlitamak: SGPI [in Russian].

Troitska O.M. (2016). Dialoh i tolerantnist' u kul'turno-osvitn'omu prostori vyshchoyi shkoly [Dialogue and tolerance in the cultural and educational space of higher education: a monograph]. Vyd-vo Bogdan Khmelnitsky Melitopol State Pedagogical University [in Ukrainian]. Troitska T.S., Osadchyi V.V. (2019). Philosophical and methodological landmarks of value and semantic information VS the "dictatorship" of digital information in the modern anthropological situation. Ukrainian journal of Educational Studies and Information Technology. (Vol. 7), (pp. 24-30) [in Ukrainian]. 